\title{
ESTUDO DAS REPRESENTAÇÕES DE PAISAGEM DE ESTUDANTES DE UMA ZONA RURAL NO OESTE DA BAHIA
}

\author{
Denise Pereira do Vale ${ }^{1}$ \\ Letícia Zenóbia de Oliveira Campos ${ }^{2}$
}

Resumo: A partir de estudos que englobam a percepção ambiental, é possível avaliar como os indivíduos percebem o meio em que estão inseridos e, assim, possibilita identificar e pontuar as possíveis causas das degradações ambientais. $O$ presente estudo buscou entender como estudantes de uma comunidade rural percebem o ambiente a sua volta e como fenômenos externos, influenciam na percepção. Foram realizadas oficinas de elaboração de redações e desenhos com estudantes, do sexto ao nono ano. Após análise dos dados, houve a realização de uma atividade de intervenção com as turmas. A partir dos resultados, foi possível observar que os estudantes conhecem diferentes aspectos ambientais vinculados à comunidades em que vivem e possuem uma visão naturalista da paisagem local.

Palavras-chave: Educação Ambiental, Ensino Fundamental, Percepção Ambiental, Representações Locais.

Abstract: Environmental perception can evaluate how individuals perceive the environment in which they are inserted and, thus, makes it possible to identify and point out the possible causes of environmental degradation. Thus, this study sought to understand how students from a rural community perceive the environment around them and how external phenomena influence this environmental representation. Workshops were held for the elaboration of essays and drawings with students, from the sixth to the ninth grade. After analyzing the data, there was an intervention activity with the classes. It was noticed that the students have a great knowledge about the community, however, they have a naturalistic view of the local landscape.

Keywords: Environmental Education, Elementary Education, Environmental Perception, Local Representations. 


\section{Introdução}

Ao longo dos anos, o meio ambiente vem sofrendo alterações ocasionadas, principalmente, pela ação antrópica. Essas mudanças na paisagem foram se intensificando nas últimas décadas, e por conta disso, hoje vivenciamos fortes impactos ambientais. Estes impactos refletem diretamente nas paisagens naturais. Neste trabalho, utilizaremos o conceito de paisagem proposto por Maximiano (2004), em que esta é vista como o resultado da relação entre os elementos naturais e sociais em um espaço. Estes elementos, por sua vez, se articulam de modo dinâmico ao decorrer do tempo (MAXIMIANO, 2004).

Nesse contexto a Educação Ambiental (EA) se torna uma ferramenta fundamental, pois segundo o Conselho Nacional do Meio Ambiente (CONAMA), a EA é definida como o processo formativo que orienta o desenvolvimento da criticidade a respeito dos problemas ambientais e ações que promovam 0 engajamento das comunidades na manutenção do equilíbrio ambiental (DIAS e DIAS, 2017). Nessa perspectiva, Sauvé (2007) compreende a EA não apenas como uma ferramenta para solucionar os problemas ambientais, mas sim, um ramo da educação que estuda as interações pessoais e sociais, que visam o desenvolvimento de atividades sociais, instigando a criticidade a respeito das questões socioambientais, o que possibilita a compreensão de conflitos e identificação de possíveis soluções. Para entender o contexto social e ambiental que o indivíduo está inserido, é necessário identificar como a população representa 0 ambiente. As representações sociais se modificam constantemente. $O$ processo de percepção do ambiente é regido por elementos internos e externos, o primeiro de caráter psicológico e genético e o segundo se refere a interação ambiental e social (DUTRA; HIGUCHI, 2018).

Levando em conta a complexidade de fatores que podem influenciar nas percepções que a espécie humana possui sobre o ambiente, entende-se que são necessárias aplicações de metodologias diversas. Entre elas podemos destacar o uso de fotografias (MONTEIRO, 2004), as entrevistas (SOUZA; ZIONI, 2003), redações (NETO, 2002) e desenhos (PEDRINI et al. 2010). De acordo com Neto (2002), o resgate das percepções por meio de redações, é importante pois o indivíduo tem a oportunidade de expressar suas opiniões, vivências, medos, dentre outros sentimentos. Em relação aos desenhos, Pedrini et al., (2010) acreditam que a representação por meio dessa ferramenta, materializa o inconsciente da criança com suas expressões simbólicas. Os desenhos produzidos pelas crianças possuem um papel fundamental na produção da representação social, sua utilização para representar sentimentos e pensamentos já é utilizada há muito tempo (SCHWARZ et al., 2016).

Essas são apenas algumas das metodologias que podem ser aplicadas. Os resultados desse tipo de estudo podem ser demonstrados em diversos trabalhos, como no trabalho de Silva et al. (2009), em que buscaram identificar a percepção de estudantes do ensino fundamental II sobre os fragmentos de Mata Atlântica que rodeava a comunidade que moravam, pertencente a cidade de Igarassu-PE. A metodologia utilizada foi dividida em três fases, a primeira foi

revista brasileira educação ambiental 
a construção de redações, onde os estudantes foram submetidos a uma frase motivadora para que escrevessem o que pensavam quando ouviam falar sobre a floresta. A segunda etapa foi a produção de desenhos e, por último, houve a ordenação de fotografias de vários ambientes urbanos e rurais, com base no nível de preferência (SILVA et al., 2019). Os autores perceberam que elementos externos e a idade poderiam ter exercido influência nas percepções dos estudantes.

Schwarz et. al. (2016) buscaram identificar as representações sociais de crianças de uma escola localizada em uma área do semiárido do México sobre a água, a metodologia utilizada foi a representação a partir de desenhos. Os autores conseguiram perceber especificidades próprias de populações residentes em ambientes rurais, como os valores, elementos do meio ambiente e a importância de viver em comunidade. Franco et al. (2012) pesquisaram as concepções de meio ambiente de estudantes de uma escola localizada próximo ao Parque Estadual da Serra do Rola Moça- $\mathrm{BH}$, e utilizaram como método de pesquisa a observação da área de estudo, análise bibliográfica e entrevistas com estudantes. Os estudantes demonstraram não possuir um conhecimento adequado do local, mesmo morando próximo. A partir do estudo, os autores identificaram a necessidade de elaborar projetos de caráter socioambiental, visando a conservação da área de proteção e, ainda, como uma forma de aproximar os indivíduos aos assuntos pertinentes à sociedade, para que estes cumpram o seu papel como cidadãos. Com isso, enfatizamos mais uma vez a importância de trabalhar esse tipo de metodologia, em áreas de zona de conflito.

Outro fator importante é que, o material didático, pode exercer uma influência negativa no aprendizado dos estudantes no que se refere aos assuntos de Educação Ambiental. Bonotto e Semprebone (2010), ao analisarem coleções de livros de ciências, perceberam conceitos problemáticos em relação ao conteúdo sobre meio ambiente. Os autores pontuaram que há um predomínio da visão antropocêntrica a respeito da natureza e ênfase do utilitarismo dos demais seres vivos. Semelhantemente, Martins e Guimarães (2002) afirmaram que os livros se limitam a apresentar conteúdo sobre meio ambiente voltados ao ecologismo, não correlacionando os conteúdos com o contexto social e político, o que contribui para que os estudantes sintam dificuldade em sensibilizar acerca dos conflitos ambientais e em buscar alternativas para resolvê-los. Uma medida que poderia ser utilizada para melhorar essa precariedade nos conteúdos de EA nos livros didáticos seria as intervenções. Elas são importantes aliadas para detectar a defasagem de conhecimentos que esses estudantes possuem e servem para intervir e quebrar barreiras em relação ao aprendizado a respeito das questões socioambientais (DAMIANI et al., 2013).

Nessa perspectiva, o presente estudo teve como objetivo identificar as representações naturais de crianças e adolescentes residentes de uma comunidade rural, localizada em uma região de conflito ambiental. O estudo da percepção dessa faixa etária, como pontua Dultra e Higuchi (2018), não se dá por preferência, mas por serem um grupo mais vulnerável às consequências socioambientais que poderão ser expostos ao longo do tempo.

Revbea, São Paulo, V.16, № 5: 134-155, 2021. 


\section{Materiais e Métodos}

A presente pesquisa foi realizada na comunidade de Malhadinha, município de Formosa do Rio Preto, localizada na região Oeste da Bahia, com estudantes da Escola Municipal Virgem de Fátima. Para tanto, foi selecionada uma amostra de 37 estudantes distribuídos entre o $6^{\circ}$ ao $9^{\circ}$ ano, com idades que variam de 11 a 16 anos.

A comunidade de Malhadinha encontra-se, exatamente, há $20 \mathrm{~km}$ do município de Formosa do Rio Preto, ao qual pertence. Por estar localizada na zona rural, há um grande predomínio de vegetação nativa na região que a rodeia, embora a monocultura já apareça dominando em locais próximos à comunidade, através de plantações como milho, soja, algodão e cana de açúcar. O Cerrado é o bioma no qual a comunidade está inserida. Malhadinha possui uma população que se agrupa em 47 famílias, que se sustentam, principalmente, da agricultura familiar, da criação de animais (galinha, porco e gado) e consumo de materiais oferecidos pela floresta local. A comunidade, atualmente, vive numa situação de conflito ambiental por conta da escassez de água aliada à agricultura. Segundo os moradores, esse problema foi ocasionado pela construção de uma barragem por proprietários de terras da comunidade, que desencadeou a seca do riacho que abastecia Malhadinha.

A escola tem uma forte influência na comunidade, desde o ensino, até na promoção de discussões que possibilitem resoluções de problemas ou propostas de melhorias para a localidade. Diante da relevância da escola para a comunidade, e do ambiente em que está inserida, esta foi selecionada para a execução da pesquisa de percepção da paisagem local.

\section{Coleta de dados de percepção ambiental}

Para diagnosticar a percepção ambiental, é de suma importância apropriar-se da metodologia qualitativa. No entanto, é válido que ela esteja atrelada ao método quantitativo, pois segundo Minayo (2002), ambas as técnicas se completam.

Vale ressaltar que a presente pesquisa foi aprovada pelo Comitê de Ética em pesquisas com seres humanos da Universidade Federal do Oeste da Bahia (UFOB), CAE n 90290918.1.0000.8060. Após o contato inicial com a escola, foi entregue um Termo de Assentimento Livre e Esclarecido (TALE), anexo ao trabalho (modelo) disposto na resolução n. 196 do Conselho Nacional de Saúde, que resguarda a permissão para participar da pesquisa. Nesse estudo, os responsáveis permitiram a participação dos estudantes.

Para a coleta de dados foram realizadas oficinas participativas, nas quais utilizamos duas metodologias: a primeira foi para que os alunos representassem o ambiente a partir de histórias (redação) e a segunda que realizassem a representação a partir de desenhos. As frases e perguntas norteadoras tanto para a história quanto para o desenho foram as seguintes: "quando lembro da 
mata eu penso em:" e "quais os elementos naturais que você percebe nas paisagens que você tem contato?" Os alunos foram orientados a identificar, tanto no texto quanto no desenho, elementos que revelassem o ambiente natural que tiveram contato durante toda sua vida. Nos desenhos, foi solicitado que nomeassem cada espécie que representaram.

Por fim, realizamos uma intervenção, que teve como objetivo abordar os assuntos pertinentes sobre percepção da paisagem, levando em consideração as suas respostas na atividade realizada e, assim, contribuir para ressignificar alguns conceitos. Foram realizadas explanações através de slides contendo o resultado da análise das oficinas e posteriormente, foram convidados a ouvirem uma música e a participarem de uma dinâmica.

\section{Análise dos dados}

Para análise do material obtido a partir das oficinas, inicialmente foi utilizada a análise de conteúdo de Bardin (1977). Foram extraídos os fragmentos e as ilustrações que mais se destacaram (mais se repetiram) nos textos e nos desenhos de cada série. Para Bardin (1977), categorias são espécies de gavetas que possibilitam a classificação dos dados construtivos da mensagem. As categorias foram criadas a partir da análise das redações e dos desenhos, não sendo pré-estabelecidas antes da coleta de dados. As categorias foram as seguintes:

a) Utilitária: incluiu todos os fragmentos que se referem à utilização da mata (floresta) como recurso, sendo estes subdivididos em subcategorias: alimentícia (quando atribuíam a utilização dos elementos da natureza para fins alimentícios), madeireiro (refere-se ao uso de madeira para construção de móveis e obtenção de lenha) e medicinais (utilização de recursos no tratamento de doenças);

b) Preservação: incluiu todos os discursos de cuidado e preocupação com o bem-estar da natureza;

c) Sentimento: abrangeu as sensações (algo subjetivo) como medo, alegria e angústia;

d) Ação antrópica: entendida como o desmatamento, poluição e, consequentemente, degradação da paisagem provocada pelo homem;

e) Comportamento de sobrevivência: inclui os conhecimentos que eles possuem sobre o ambiente através de observações cotidianas, ou até mesmo por conhecimentos populares.

Os fragmentos extraídos dos textos foram agrupados em categorias (utilitária, preservação, sentimento, ação antrópica, comportamento de sobrevivência), assim, foi possível quantificar o número de vezes que esses discursos foram citados. Isso facilitou a comparação dos dados e obtenção dos resultados, demonstrando se as histórias são fatos cotidianos ou se tem uma abordagem lúdica influenciada por desenhos animados ou filmes da televisão. 
Além de, possibilitar a comparação das diferenças e/ou semelhanças nas respostas de cada turma.

Por fim, utilizamos a análise do Discurso do Sujeito Coletivo de Lefevre e Lefevre (2014). Essa metodologia foi utilizada após o agrupamento dos fragmentos em categorias (descritas acima), possibilitando a construção do discurso do sujeito coletivo para cada uma das séries, levando em consideração a ideia central de cada redação.

$\mathrm{Na}$ análise dos desenhos, levamos em consideração três categorias: a) flora, b) fauna e os c) elementos abióticos (SILVA et al. 2009). Essa categorização gerou uma tabela que permitiu identificar a quantidade de ilustrações demonstradas em cada categoria. Isso possibilitou comparar os animais, plantas, elementos e ambientes que eles representaram nos desenhos com o que eles têm contato nos locais em que vivem e o que é apresentado nos livros didáticos. É uma forma de identificar se o ensino é contextualizado com a cultura local ou se é apenas transposto o que está nos livros didáticos.

Após a categorização dos dados, foi utilizado o teste estatístico de Kruskal - Wallis para observar se existiam diferenças significativas entre os desenhos das diferentes series. Para isso, foram calculados a quantidade de representações dispostos em cada categoria estabelecida no presente trabalho e, esses dados possibilitaram comparar as diferentes turmas.

Adicionalmente, para identificar se o livro didático exerceu alguma influência nos discursos desses estudantes, analisamos o conteúdo disposto no livro de Ciências do sexto, sétimo, oitavo e nono. A análise foi feita a partir da observação do sumário.

\section{Resultados e discussão}

\section{Análise dos discursos coletivos}

A partir desse momento, apresentaremos a análise do discurso coletivo de cada uma das séries que participaram da pesquisa, também ilustrada na Tabela 1. Para construção do discurso do sujeito coletivo do sexto ano foram analisadas sete redações, resultando no seguinte discurso:

"Quando lembro da mata me sinto feliz. Lembro das frutas, dos animais. Não pode botar fogo na mata. Os animais não sobrevivem na floresta se destruímos. Da natureza conseguimos apanhar frutas e remédios. E lenha para fazer o alimento. Gostamos da mata. Temos que cuidar muito do meio ambiente. Não podemos desmatar. Vamos replantar."

De acordo com as expressões-chave, percebe-se uma grande utilização da mata para fins utilitários, evidentes em 11 fragmentos. Eles já entendem a importância dela para sobrevivência, como na expressão " $\mathrm{Da}$ natureza conseguimos apanhar frutas e remédios". Esse mesmo comportamento foi identificado nos estudos de Silva et al. (2015), em um estudo das representações de estudantes de ensino médio em áreas urbanas e rurais numa Área de 
Proteção Ambiental (APA) no estado de Pernambuco. Teles (2015) descreve concepções semelhantes em sua dissertação, onde aponta a grande incidência da visão antropocêntrica e utilitária de estudantes em relação ao meio ambiente. Nesse sentido, o homem é visto como ser superior e a natureza como um recurso útil para a nossa sobrevivência.

Além disso, há uma preocupação em preservar o meio ambiente, presente em 12 fragmentos das redações, "temos que cuidar muito do meio ambiente", e apontam também as consequências das ações do homem, dispostos em quatro trechos, quando citam, por exemplo, a questão do fogo e o desmatamento. Silva et. al. (2009) e Teles (2015) apresentaram resultados que corroboram com esses dados. Aires e Bastos (2011), através de mapas mentais desenvolvidos por estudantes, puderam perceber um elevado número de elementos em suas representações gráficas que remetiam a ambientes preservados, como: serras, rios e árvores.

Os estudantes demonstraram, também, um sentimento positivo pela natureza, "quando lembro da mata me sinto feliz", representados em três fragmentos. Esse sentimento é caracterizado, por Tuan (1980), como topofilia, um elo afetuoso entre o indivíduo e o ambiente. Silva et al. (2009) consideram que, geralmente, esse aspecto sentimentalista está relacionado à idade, crianças tendem a ter uma certa admiração pela natureza.

Uma outra categoria identificada foi a de comportamento de sobrevivência, detectado em seis trechos, "os animais não sobrevivem na floresta se destruímos", esse tipo de comportamento muitas vezes está atrelado ao conhecimento adquirido pelo senso comum ou através de observações. Freire (2011) defende que não devemos desprezar o conhecimento que crianças e jovens trazem consigo sobre como compreendem o mundo a sua volta. Dessa forma, é de suma importância nos apropriarmos do conhecimento advindo das vivências desses estudantes.

Um total de nove redações foram analisadas para construção do discurso do sétimo ano, com destaque para a redação transcrita abaixo:

"Lembro de cachoeira, rochas, árvores, rios, matas e animais... São essenciais para nossa sobrevivência. Gosto de ir no rio tomar banho. Na mata que encontro as frutas. A natureza é bem valorizada pelos animais. Um dia eu queria morar na mata. É muito legal brincar na mata. Se não fosse as árvores não teríamos sombra. As árvores servem para fazer lenha. E para pegar madeira para fazer papel. Elas que dão o ar. Não podemos queimar e nem cortar as árvores. Tão acabando com a natureza. Temos que preservar o que temos para nunca perder. Se a natureza morre nós todos morremos, mas ela volta e nós não."

Foram encontrados 20 fragmentos nas redações que remetiam à categoria utilitária, "as árvores servem para fazer lenha" em relação ao sexto ano, o sétimo ano apresentou uma visão mais utilitária da mata, pois apresentaram uma quantidade maior de fragmentos que remetem ao utilitarismo. Percebe-se, em vários discursos a predominância da natureza como meio de 
subsistência. Dados semelhantes foram encontrados no trabalho de Silva et. al. (2015), onde estudantes residentes em comunidades atribuíram mais importância aos benefícios da natureza, como a lenha e fontes de água.

A preservação do meio ambiente foi percebida em 15 fragmentos, "não podemos queimar e nem cortar as árvores". Embora todos as séries apresentaram preocupações em relação à preservação, os estudantes do sétimo ano apresentaram um valor mais elevado em relação as outras turmas, se comparado ao número de redações analisadas. Esse resultado pode estar atrelado ao que foi estudado na escola ou ao fato de que com o avançar da idade a criança tende a desenvolver esse discurso preservacionista. Bezerra et al. (2014), ao realizarem um estudo sobre a percepção ambiental com estudantes do ensino fundamental II, constataram que todas as turmas, com exceção do sexto ano, sabiam o que era desenvolvimento sustentável, e dentre as séries a que mais apresentou esse conhecimento foi o sétimo e o nono ano. Eles atrelaram desenvolvimento sustentável a preservação da natureza.

As consequências das ações antrópicas foram citadas quatro vezes, assim como na turma anterior, "tão acabando com a natureza". É perceptível, em vários trechos das redações, que os estudantes têm consciência do mal que o ser humano está causando com suas ações. Dutra e Higuchi (2018) constataram que $22,5 \%$ das crianças que moravam em torno de uma lagoa consideraram a degradação como uma característica desse local, isso porque percebiam que aquele ambiente sofreu alterações indevidas pelo homem, como a poluição pelo acúmulo de lixo. O que demostra que as crianças e adolescentes já são capazes de perceberem os efeitos das ações antrópicas, como foi observado no presente trabalho.

O sentimentalismo foi exposto em quatro fragmentos, "um dia eu queria morar na mata". Esse sentimento de pertencimento caracterizando o ambiente como moradia é entendido por Dutra e Higuchi (2018) como um local de proximidade e de uma junção de valores o tornando como parte de seu lar. No seu estudo, $13,4 \%$ das crianças entendiam o ambiente natural estudado como parte de sua casa, onde realizavam atividades como tomar banho e lavar roupa, por exemplo. Demonstrando que há um vínculo com o ambiente natural que têm contato, como o que foi observado na turma do sétimo ano.

O comportamento de sobrevivência foi expresso em 11 trechos das redações, "se a natureza morre nós todos morremos, mas ela volta e nós não." Essa mesma frase foi repetida nos discursos do oitavo e nono ano. Isso pode estar atrelado a alguma atividade desenvolvida em sala de aula, ou até mesmo a um projeto de restauração ambiental que estava sendo desenvolvido na comunidade e que tinha o apoio da escola.

Para a construção do discurso do oitavo ano foram analisadas 15 redações, resultando no seguinte discurso: 
"Lembro das árvores, plantas, paisagens, riachos, frutas e animais. Penso na fonte de água que as nascentes fornecem. Ninguém vive sem a água. Se não tivesse as matas não tinha animais. O mato é um lugar de brincar. As árvores transmitem $o$ ar que respiramos. Penso nos animais que vivem nela e que precisam dela para sobreviver. Muita gente não gosta da natureza porque não vive com eles. É falta de respeito cortar árvores. Quando a mata acabar as fontes de água acaba. Minha mãe e minha avó me falam que o riacho era muito bonito, tinha água o ano todo, tinha areia e muitas árvores ao seu redor... Se não tivesse as árvores não tinha o lápis. A natureza está sendo destruída. O homem vai e mata os animais. Antes do homem tinha muita madeira. Cortar algumas árvores, fazer barragem afeta muito o meio ambiente. Quase todo ano tem incêndio. A maioria das queimadas são causadas por caminhoneiros. O trator e o fogo tá acabando com a mata. Se a natureza morre nos também morremos. Deus cuida de nossa mata. A natureza é o melhor lugar do mundo."

O discurso utilitário se fez presente em 28 fragmentos das redações, "Minha mãe e minha avó me falam que o riacho era muito bonito, tinha água o ano todo, tinha areia e muitas árvores ao seu redor." É interessante destacar a transmissão de informações entre gerações, que é perceptível em vários trechos das redações. A comunidade vem sofrendo uma crise hídrica nessas últimas décadas, por isso todas as turmas apresentaram em seus relatos questões relacionadas à água, principalmente a sua importância e utilidade.

Silva et al. (2006) desenvolveram um estudo de percepção sobre o uso da água das cisternas em comunidades, dentre os aspectos avaliados está a importância da água. Os autores utilizaram uma dinâmica para diagnosticar as concepções de famílias das comunidades sobre a importância desse recurso, e todos apresentaram discursos utilitários, como a importância para as necessidades pessoais, para agricultura e para os animais, corroborando com os que obtivemos em nossa pesquisa.

A preservação do meio ambiente foi expressa em 11 trechos, "é falta de respeito cortar árvores". O desmatamento tem sido muito recorrente em nosso bioma. Se considerarmos a região Oeste da Bahia, o cenário é ainda mais complexo, principalmente por conta do avanço da fronteira agrícola para implementação de monoculturas. Como ocorre na comunidade de Malhadinha, onde há um conflito ambiental entre os donos de terras e os moradores locais.

As ações antrópicas puderam ser evidenciadas em 17 fragmentos, um número quatro vezes maior em relação às outras séries. "O homem vai e mata os animais", a caça ilegal é um grave problema que vem colocando em risco a nossa diversidade faunística. Teles (2015) constatou discursos semelhantes em sua pesquisa com estudantes de uma comunidade, porém considerou como pequeno o número de estudantes que consideram "não matar os animais" uma atitude de preservação. Diante disso, o autor propõe a importância de abordar esse tema, levando em consideração os desequilíbrios ecológicos que podem acarretar sérios problemas para nosso meio ambiente. Percebemos nesse caso, que a turma do oitavo ano apresentaram um grande conhecimento sobre os 
malefícios das ações antrópicas e, ainda, sobre a importância dos animais para o equilíbrio ambiental.

O sentimento foi identificado apenas duas vezes nas redações, "a natureza é o melhor lugar do mundo". Assim como o sexto e o sétimo ano, os sentimentos em relação à natureza foram em sua maioria positivos. Pereira, et al. (2018), ao pesquisarem a percepção ambiental de moradores de zonas urbanas a respeito das unidades de conservação que os rodeiam, perceberam que eles apresentaram em sua grande maioria sentimentos positivos, o qual os autores caracterizam como topofilia.

A categoria comportamento de sobrevivência foi identificada em 13 trechos, "Muita gente não gosta da natureza porque não vive com eles", um dos pressupostos da Educação Ambiental é conhecer para preservar. Os estudantes deixaram claro que "há uma maior valorização da natureza pelas pessoas que têm mais proximidade com ela", demonstrando que há uma forte interação dos estudantes pelo ambiente local, o que contribui para o desenvolvimento desse apego a natureza.

Por fim, para a construção dos discursos do nono ano, foram analisadas seis redações, gerando o seguinte relato:

"Eu penso em tudo de bom que a vida nos oferece, dos animais, paisagens naturais e das plantas. Lembro das frutas saudáveis que nascem e crescem nas árvores sem precisar de agrotóxicos. Muitos animais sobrevivem da água dos rios. Sem a mata os rios vão secar. Temos que cuidar das nossas nascentes, especialmente da nossa comunidade que está precisando de cuidados ao riacho da Malhadinha e ao Rio Preto. As queimadas causam muito estrago. No local que ele colocou fogo não vai mais nascer árvore. Fiquei muito triste vendo meu tio derrubando a árvore. Meu tio disse que derrubar as árvores é um modo de sobrevivência para manter a família. Dependemos das plantas medicinais. E dependemos da lenha para cozinhar. Já andei muito procurando mangaba, pequi, mutamba, caju, manga, maracujá para fazer suco. Nós estamos aqui pra não deixar os animais irem à extinção. Animais que ajudam a preservar a mata. A natureza vive sem nós, mas nós não sobrevivemos sem ela. Tem os animais que vivem na mata como: as onças, ursos".

O discurso utilitarista foi encontrado em 16 fragmentos das redações, "Já andei muito procurando mangaba, pequi, mutamba, caju, manga, maracujá para fazer suco.", nota-se que os estudantes trazem em seus textos muitas frutas típicas da região, remetendo que conhecem a flora local. Um outro fato curioso é que a grande maioria citou a manga e o caju em seus textos, isso pode estar relacionado ao período de frutificação deles, pois a pesquisa aconteceu no mês de outubro, época propícia para colheita desses frutos na região, importante ressaltar que essas frutas são considerada exóticas, ou seja, não são típicas da região.

A respeito da preservação, foram encontrados 12 trechos, "temos que cuidar das nossas nascentes". Como já foi mencionado, a comunidade vem 
sofrendo com a escassez de água, por isso, medidas de preservação devem ser tomadas. Nesse sentido, é muito importante que esses estudantes tenham esses pensamentos preservacionistas, visto a necessidade de eles tomarem atitudes para amenizar essas situações de conflitos ambientais na comunidade. Silva et al. (2009) acreditam que esses discursos conservadores são mais acentuados em estudantes de 14 a 21 anos de idade, isso porque nessa idade eles já possuem um grau de maturidade mais elevado.

A ação antrópica foi perceptível em cinco trechos, "no local que ele colocou fogo não vai mais nascer árvore", em comunidades rurais ainda há o hábito de colocar fogo na vegetação como forma de "limpar o pasto". Essa queima é feita no período da seca, para brotarem na época das chuvas. No entanto, com as constantes queimadas, ao invés de benefícios, o que gera são inúmeros malefícios, não só para o pasto, mas também causa sérios prejuízos financeiros ao pecuarista (EMBRAPA, 2002). Sabemos que o clima seco é bastante favorável a propagação do fogo, e esse clima é característico do Cerrado, por isso nos meses que ele é mais intenso ocorre uma grande incidência de incêndios nessas regiões.

O sentimentalismo apareceu seis vezes em seus textos. Encontramos sentimentos que remetem a indignação, insatisfação e repúdio a respeito do desmatamento, "fiquei muito triste vendo meu tio derrubando a árvore", isso demonstra que há uma proximidade com a natureza, a ponto de sofrer ao vê-la ser destruída. Isso é reconhecido como valores ambientais, que foram construídos a partir da relação com o ambiente natural da comunidade, permitindo que o indivíduo interprete e atue no meio natural (PEREIRA et al., 2018).

Como comportamento de sobrevivência encontramos sete fragmentos, "têm os animais que vivem na mata como: as onças, ursos". Apesar dos estudantes em sua grande maioria demonstrarem conhecimento sobre a fauna e flora local, uma pequena minoria apresentaram animais que não são típicos da região, como nesse trecho, onde citaram a presença de ursos e onças. Silva et al. (2009) encontraram frases semelhantes em sua pesquisa sobre percepção ambiental, eles atribuem esses dados a influência da mídia ou também do livro didático, que muitas das vezes não abordam os conteúdos de forma contextualizada.

A Tabela 1 resume os resultados obtidos: 
Tabela 1: Classificação dos fragmentos contidos na redação dos estudantes de sexto ao nono ano da escola Nossa Senhora de Fátima, Malhadinha, Oeste da Bahia, Brasil.

\begin{tabular}{ccccccc}
\hline Ano & $\begin{array}{c}\mathbf{N}^{\circ} \text { de } \\
\text { estudantes }\end{array}$ & Utilitária & Preservação & Sentimento & $\begin{array}{c}\text { Ação } \\
\text { antrópica }\end{array}$ & $\begin{array}{c}\text { Comportamento } \\
\text { de sobrevivência }\end{array}$ \\
\hline $\mathbf{6}^{\circ}$ & 07 & 11 & 12 & 03 & 04 & 06 \\
\hline $\mathbf{7}^{\circ}$ & 09 & 20 & 15 & 04 & 04 & 11 \\
\hline $\mathbf{8}^{\circ}$ & 15 & 28 & 11 & 02 & 17 & 13 \\
\hline $\mathbf{9}^{\circ}$ & 06 & 16 & 12 & 06 & 05 & 07 \\
\hline
\end{tabular}

Fonte: Tabela produzida a partir dos dados levantados apresentados neste trabalho.

\section{Análise dos desenhos: listagem de elementos bióticos - fauna e flora e abióticos}

Em relação aos desenhos, não foram encontradas diferenças significativas no número de elementos representados entre as diferentes séries $(H=0,8 p \geq 0,05)$. No geral, os estudantes representaram o meio ambiente como um local belo e agradável (Figura 1). Dados semelhantes a esses foram encontrados em um trabalho de Santos et al. (2017), em sua pesquisa com licenciandos durante atividades de extensão universitária, em que utilizaram o desenho como ferramenta para diagnosticar a percepção que esses indivíduos tinham do meio ambiente. Ao analisar os desenhos, os autores criaram cinco categorias, dentre elas, a de percepção romântica, quando o indivíduo tem uma concepção de que a natureza é bonita e intocada pelo homem, havendo uma predominante presença de elementos da natureza. No nosso estudo, essa percepção romântica pode ser evidenciada nos desenhos através da representação de um ambiente totalmente naturalizado, composto por rios, plantas, animais, montanhas, sol, nuvens e nenhum tipo de interferência humana.
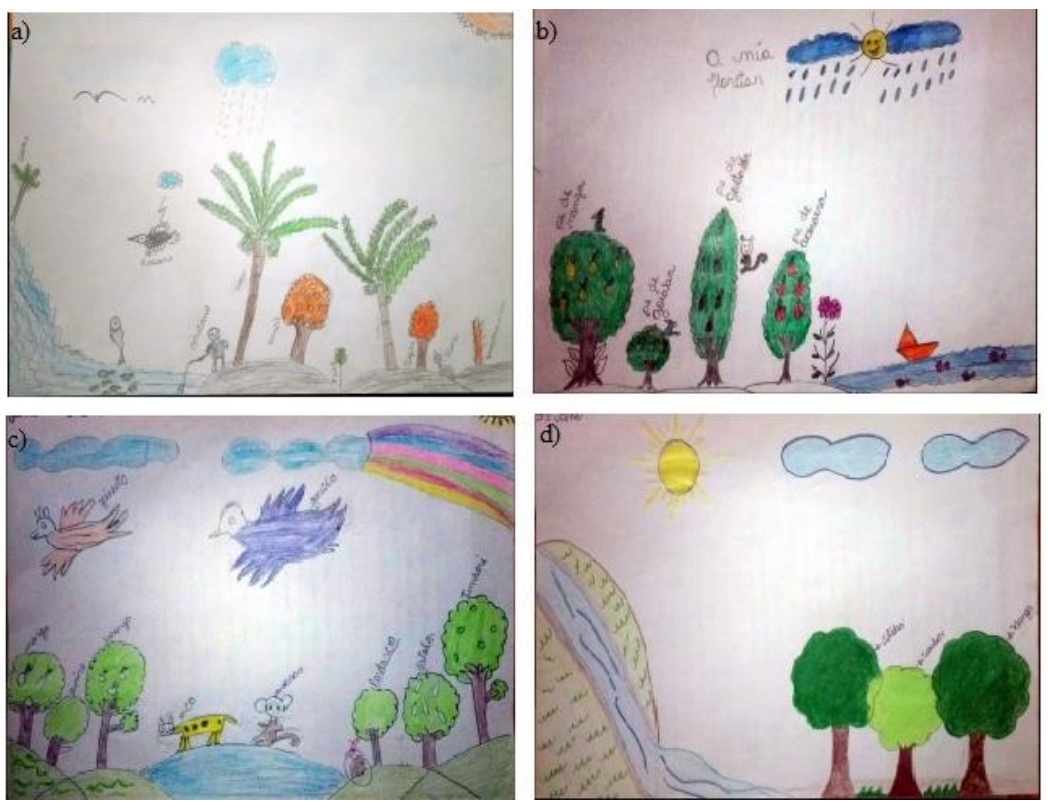

Figura 1: Imagem dos desenhos de representação de paisagem de estudantes do sexto ano (a), sétimo ano (b), oitavo ano (c) e nono ano (d), da Escola Municipal Virgem de Fátima, Comunidade Malhadinha - Formosa do Rio Preto, Bahia, Brasil. 
Reigada e Reis (2004) encontraram resultados semelhantes, em seu estudo com crianças que residiam em um bairro popular de Botucatu, em que não representaram nos desenhos elementos referentes ao meio urbano, somente elementos naturais. No entanto, Dultra e Higuchi (2018), tiveram resultados divergentes, ao solicitarem que crianças do $1^{\circ}$ ao $8^{\circ}$ ano, residentes do entorno de uma lagoa, desenhassem a lagoa com o que havia lá e o que poderiam fazer nesse local. O que demonstra que a percepção do ambiente pode variar e diversos fatores podem contribuir para isso.

Os elementos representados nos desenhos foram categorizados em três grupos: fauna, flora e elementos abióticos (Tabela 2). Na categoria fauna, o sexto ano apresentou um total de sete animais, dentre eles, o ser humano. Esta foi a única turma a representar o ser humano em seus desenhos. Luz et al. (2018) encontraram dados similares em estudos com crianças de sete a 11 anos sobre a concepção de meio ambiente através de desenhos, onde puderam notar, inicialmente, que essas crianças apenas consideram os elementos abióticos e bióticos como meio ambiente, além disso, não se consideram como parte dele, apesar de que em um dos desenhos uma estudante tenha se auto representado. Os autores consideraram que o ambiente desenhado não parece propício para viver, já que não apresentam nenhum vestígio da cultura antrópica, como casas, prédios, transportes, pessoas, eles acreditam que a criança só estava de passagem naquele local, e o considera como natureza intocada. Essa pode ser a explicação para o sexto ano ter representado o ser humano.

Tabela 2: Incidência de fauna, flora e elementos abióticos nas representações dos alunos de sexto ao nono ano da Escola Nossa Senhora de Fátima, Comunidade de Malhadinha,

Formosa do Rio Preto, Bahia, Brasil.

\begin{tabular}{cccccc}
\hline Categoria & Representação & $\mathbf{6}^{\mathbf{0}}$ ano & $\mathbf{7}^{\mathbf{0}}$ ano & $\mathbf{8} \mathbf{a} \mathbf{a} \mathbf{0}$ & $\mathbf{9}$ ano \\
\hline Fauna & Pássaros & 0 & 2 & 2 & 0 \\
\hline Boi & 0 & 1 & 0 & 0 \\
\hline Peixe & 1 & 5 & 1 & 1 \\
\hline Macaco & 1 & 1 & 1 & 0 \\
\hline Borboleta & 0 & 1 & 1 & 1 \\
\hline Raposa & 0 & 1 & 0 & 0 \\
\hline Ser humano & 1 & 0 & 0 & 0 \\
\hline Vaca & 1 & 0 & 0 & 0 \\
\hline Gato & 1 & 0 & 0 & 0 \\
\hline Tatu & 1 & 0 & 1 & 0 \\
\hline Veado & 1 & 0 & 0 & 0 \\
\hline Gaivota & 0 & 0 & 1 & 0 \\
\hline Onça & 0 & 0 & 1 & 0 \\
\hline Gavião & 0 & 0 & 1 & 0 \\
\hline Tamanduá & 0 & 0 & 1 & 0 \\
\hline Total: & $\mathbf{7}$ & $\mathbf{1 3}$ & $\mathbf{1 0}$ & $\mathbf{2}$ \\
\hline
\end{tabular}

Continua...

Revbea, São Paulo, V.16, № 5: 134-155, 2021. 
continuação.

\begin{tabular}{|c|c|c|c|c|c|}
\hline Categoria & Representação & 60 ano & $7^{\circ}$ ano & $8^{\circ}$ ano & 9 ano \\
\hline \multirow[t]{24}{*}{ Flora } & Maçã & 2 & 2 & 2 & 0 \\
\hline & Coco & 4 & 3 & 1 & 1 \\
\hline & Manga & 4 & 5 & 5 & 4 \\
\hline & Laranja & 2 & 3 & 6 & 0 \\
\hline & Flor & 2 & 3 & 5 & 1 \\
\hline & Caju & 4 & 3 & 1 & 1 \\
\hline & Mandacaru & 1 & 0 & 0 & 0 \\
\hline & Pêra & 1 & 0 & 0 & 0 \\
\hline & Jatobá & 2 & 1 & 1 & 1 \\
\hline & Ipê & 1 & 0 & 1 & 0 \\
\hline & Jabuticaba & 1 & 0 & 0 & 0 \\
\hline & Jaca & 0 & 1 & 0 & 0 \\
\hline & Uva & 0 & 1 & 0 & 0 \\
\hline & Grama & 0 & 1 & 4 & 2 \\
\hline & Goiaba & 0 & 1 & 0 & 0 \\
\hline & Acerola & 0 & 1 & 0 & 0 \\
\hline & Tamarindo & 0 & 1 & 0 & 0 \\
\hline & Oiti & 0 & 1 & 0 & 0 \\
\hline & Aroeira & 0 & 0 & 1 & 0 \\
\hline & Tambori & 0 & 0 & 1 & 2 \\
\hline & Pequi & 0 & 0 & 2 & 0 \\
\hline & Limão & 0 & 0 & 1 & 0 \\
\hline & Arvores & 0 & 0 & 1 & 2 \\
\hline & Total: & 24 & 27 & 32 & 14 \\
\hline \multirow[t]{14}{*}{$\begin{array}{c}\text { Elementos } \\
\text { abióticos }\end{array}$} & Nuvens & 4 & 6 & 9 & 5 \\
\hline & Sol & 4 & 5 & 8 & 5 \\
\hline & Chuva & 2 & 4 & 0 & 1 \\
\hline & Rio & 1 & 1 & 3 & 2 \\
\hline & Montanhas & 1 & 1 & 0 & 0 \\
\hline & Cachoeira & 0 & 1 & 0 & 3 \\
\hline & Raio & 0 & 1 & 0 & 0 \\
\hline & Solo & 0 & 2 & 0 & 0 \\
\hline & Estrela & 0 & 0 & 1 & 0 \\
\hline & Arco-íris & 0 & 0 & 1 & 0 \\
\hline & Rocha & 0 & 0 & 1 & 1 \\
\hline & Riacho & 0 & 0 & 0 & 1 \\
\hline & Terra & 0 & 0 & 0 & 1 \\
\hline & Total: & 12 & 21 & 23 & 19 \\
\hline
\end{tabular}

Fonte: Tabela produzida a partir dos dados levantados apresentados neste trabalho.

No sétimo ano foram identificados 13 vezes a representação faunística, sendo este o que mais se destacou em relação às outras turmas, porém, com baixa diversidade. $O$ curioso é que dos 13 animais, cinco foram peixes (o único animal representado em comum com as outras turmas), lembrando que o único riacho da comunidade secou. 
No oitavo ano, foram identificados dez elementos faunísticos, e esta foi a turma que mais trouxe diversidade de animais. Isso pode estar relacionado ao conteúdo trabalhado em sala de aula sobre o Reino Animalia. Já o nono ano, foram os que menos apresentaram animais em suas representações, apenas dois. Para Schwarz et al. (2016) o resultado obtido pelas representações de crianças a respeito da paisagem natural é a consequência de sua interação com o ambiente. Segundo os autores, as crianças tendem a representar aquilo que apresenta mais significado para sua vida. Essa pode ser a explicação para o número significativo de peixes, pois, com o esgotamento do rio, esse animal provavelmente se tornou escasso na região.

As turmas apresentaram um número maior de flora, se comparado ao número de fauna e elementos abióticos, com exceção do nono ano, que trouxeram mais elementos abióticos. O sexto ano representou a flora 24 vezes em seus desenhos, o sétimo ano apresentou 27 desenhos relacionados à flora, inclusive, junto com o oitavo ano, foram as turmas que mais trouxeram diversidade de flora. $\mathrm{O}$ oitavo ano apresentou 32 plantas, e nono ano, apenas 14.

Pedrini et al. (2010) encontraram resultados contraditórios ao analisarem a percepção de crianças em uma instituição privada de acolhimento em detrimento de violências sexuais ou sociais. A pesquisa foi realizada através da produção de desenhos, onde as crianças representaram sua concepção sobre meio ambiente. Em seus resultados, perceberam que houve mais elementos da fauna e da atmosfera do que da flora e, ainda, foi observado animais de outros países. Isso demonstra que a grande presença de elementos da flora em nosso estudo pode estar relacionado ao fato de que esses estudantes têm mais contato com esses elementos, diferente das crianças que residem em ambientes urbanos. No estudo de Luiz et al. (2018), também constataram a predominância de flora em relação aos outros elementos em sua pesquisa com crianças, concluindo que isso pode estar relacionado às cores que são atrativas, ou até mesmo por elas terem mais proximidade.

Os elementos abióticos foram menos visíveis nas representações do sexto ano. Apenas 12, enquanto no sétimo foram 21, oitavo ano 23 e nono ano 19. Todas as turmas representaram nuvens, sol e rio, esses inclusive, foram os mais citados. A representação da chuva também esteve bastante presente, exceto a turma do oitavo ano que não trouxe esse elemento em seus desenhos. O que chama atenção é que, como já foi citado, a comunidade enfrenta problemas com a falta de água e, ainda, o período de chuva é bem curto, isso quer dizer que o rio e a chuva não são elementos que caracterizam a paisagem daquele local. Schwarz (2016) estudou o conhecimento de crianças sobre a água em uma comunidade rural do México através da construção de desenhos e percebeu que as crianças representaram com mais frequência a chuva $(74 \%)$, rios $(74 \%)$ e nuvens $(73 \%)$, os autores acreditam que esse resultado possa ser devido à escassez desse recurso, o que gera uma expectativa pela sua chegada. Esse pode ser o motivo dos estudantes apresentarem tanto esses recursos no nosso estudo.

Revbea, São Paulo, V.16, № 5: 134-155, 2021. 


\section{Análise dos livros didáticos}

Ao analisar se o livro didático de Ciências influenciou nos discursos e representações das diferentes séries obtivemos a conclusão de que o sexto ano, em relação a quantidade de textos e desenhos analisados, foram os que apresentaram maior diversidade de elementos bióticos (fauna e flora). Porém, em relação aos elementos abióticos trouxeram bem menos variedades, se comparados aos outros anos. Isso demonstra que livro o didático "Planeta Terra" (GEWANDSZNAJDER, 2015) pode ter influenciado, já que ele aborda os seres vivos e suas interações. No entanto, percebe-se que pouco relacionam esses seres vivos aos elementos abióticos, já que em comparação às outras séries, eles representaram bem menos variedades. Em relação às redações, percebese que há uma grande preocupação com a preservação da natureza e as consequências da ação antrópica, isso também pode estar atrelado ao conteúdo estudado no livro didático.

Já o sétimo ano, trouxe uma grande variedade de fauna, flora e elementos abióticos em suas representações, o que demonstra que o livro didático "Vida na Terra" (GEWANDSZNAJDER, 2015) possa ter influência, já que dentre os assuntos abordados estão o reino animal, vegetal e o ambiente. Além disso, a presença de elementos abióticos pode estar relacionado ao fato de que o sexto e sétimo anos dividem a mesma sala. Assim como nos desenhos, nos textos, também, citaram muitos elementos da fauna e flora (estes em grande maioria são nativos da região), e sinalizaram a importância desses elementos, enfatizando a preservação.

No oitavo e nono, o livro didático não apresentou tanta influência, já que o conteúdo não é referente ao meio ambiente. O que podemos perceber é que apresentaram uma maior preocupação em relação ao utilitarismo e preservacionismo, isso pode ser devido ao grau de maturidade que esses adolescentes possuem.

Martins e Guimarães (2002) criticam a forma como os conteúdos estão dispostos no livro didático, sendo que na maioria das vezes, encontra-se fragmentado, contribuindo para distorcer a visão de que tudo está interligado. Esse mesmo autor acrescenta que, muitas vezes, a natureza é representada nos livros como uma obra perfeita e o homem como o causador dos desmatamentos, porém, ao utilizar a palavra homem, remete a ideia de que a responsabilidade não é individual, como se não fizéssemos parte da natureza. Por isso deve existir uma atenção por parte dos professores com a utilização do livro didático, que muitas vezes ainda apresentam conteúdos que não condizem com a realidade do estudante.

\section{Intervenção}

Após a análise dos dados obtidos nas oficinas de desenho e redação, foi desenvolvida uma atividade de intervenção com os estudantes. A finalidade dessa atividade foi apresentar os resultados do trabalho desenvolvido por eles

revista brasileira educação ambiental 
e, ainda, contribuir para ressignificar alguns conceitos percebidos durante a análise. Sabendo que as crianças e jovens já possuem conceitos próprios que foram construídos a partir de interações socioculturais, é importante lidar com esses conhecimentos, a fim de provocar um diálogo entre conceitos empíricos e o científico (HENTZ, 1998). Freire (2011) considera importante aproveitar os saberes que cada estudante possui sobre o ambiente que estão inseridos e, ainda, aliar esses conhecimentos ao ensino dos conteúdos.

Inicialmente, relembramos da oficina que havia ocorrido há meses, como já estavam em outro ano letivo, os estudantes do nono ano já haviam saído da escola, porém, a turma do sexto ano (que não participou da pesquisa, pois ano passado eles eram do quinto ano) participaram da intervenção.

Após isso, iniciamos uma pequena explanação dos resultados, através de slides. A apresentação foi dividida em oito lâminas, cada uma delas com um assunto abordado por eles em suas redações. O primeiro foi "Como o homem vem se comportando em relação a natureza?" Abaixo haviam os trechos de suas redações que respondiam à pergunta. Dentre esses trechos: "há uma destruição na floresta que é o fogo", por essa questão de o fogo ser tão debatida por eles, abordamos algumas possíveis causas desses incêndios, como a renovação da pastagem, a queima de lixo nos quintais e a predominância do clima seco, que contribui para que o fogo se alastre. Além do fogo, abordamos a questão do desmatamento e da poluição da água, que foi também muito recorrente nos textos. Aproveitamos para tentar estimulá-los a apaziguar essa situação de degradação do ambiente causado pela ação antrópica.

Como a água foi um tema muito recorrente nos textos, trouxemos a sua importância, através do trecho: "minha mãe e minha avó me falam que o riacho era muito bonito, tinha água o ano todo...", discutimos sobre a escassez de água, mas que há algumas décadas isso não existia, por isso, os questionamos sobre o que levou a esse rio se esgotar? Remetendo, justamente, às ações antrópicas. Além de ressaltar que essa escassez da água não afeta somente nós, seres humanos, mas todos os seres vivos, pois tudo está ligado.

Falamos também sobre a preservação da natureza, como preservar "não podemos colocar fogo na mata", e por que preservar: "é na mata que encontro as água e as frutas", onde ressaltamos a ideia da natureza ser útil para nossa sobrevivência e de outros seres vivos.

Após a apresentação, os estudantes ouviram uma música (Para Germinar- Palavra Cantada) (Anexo I). A música foi escolhida por abordar em sua letra a importância de cada ser vivo para o equilíbrio do planeta. Posteriormente, foi solicitado que eles comentassem o que perceberam na música em comum como que foi discutido anteriormente.

Por fim, realizamos uma dinâmica ${ }^{3}$ com o título: "Identificando-se com um elemento da natureza". Foi passada uma caixa contendo vários elementos

\footnotetext{
${ }^{3}$ disponível no site https://www.educacaoetransformacao.com.br/dinamica-sobre-meio-ambiente/.
} 
naturais (folha seca, areia, vagem, maçã, laranja e pedra) e os estudantes foram solicitados a pegar um elemento que teria relação com suas características pessoais e, posteriormente, eles disseram o porquê escolheram aquele elemento. No final, pedimos que devolvessem os elementos à caixa e escrevessem algo que aquela dinâmica havia despertado, seja um comentário, um conselho... Depois, foram expostas todas as frases à turma, sem que os estudantes fossem identificados. Abaixo estão algumas dessas frases:

"Despertou em mim lembranças da infância, coisas que aconteceram em minha vida..."

"A natureza é importante para todas as pessoas da comunidade."

"Me fez perceber que pequenas coisas da natureza nos faz lembrar de nossa vida, por isso temos que conservar a natureza."

"Se a gente preservar a natureza daqui a alguns anos teremos não só esses elementos, teremos mais."

Vários trabalhos trazem a importância da realização de intervenções nas escolas. Reigada e Reis (2004), ao pesquisarem a percepção ambiental de crianças de zonas urbanas, após desenvolveram várias atividades, como roda de conversa, construção de desenhos, mapas, maquetes e jogos, perceberam que tais intervenções contribuíram para a ressignificação de conceitos, mudanças de percepção do ambiente, permitiu ainda que percebessem o seu papel no ambiente e que o ambiente não se restringe aos elementos naturais, e que nós seres humanos também fazemos parte.

Luz et al. (2018) em seu trabalho, apresentaram conclusões semelhantes. Os autores perceberam que, inicialmente, as crianças residentes em uma comunidade tinham um conceito de meio ambiente bastante naturalista e, ao decorrer das nove intervenções de Educação Ambiental realizadas aliadas aos assuntos desenvolvidos pela disciplina de Ciência, constataram mudanças nas percepções das crianças, passaram a ter uma visão mais integrada do meio ambiente.

Por fim, é importante ressaltar que a escola desempenha um papel fundamental na formação de atitudes ambientais no indivíduo (Barraza, 1998). Muitas vezes, devido à falta de conhecimento sobre a importância de elementos naturais para o ecossistema, os indivíduos acabam destruindo esses elementos, por acreditarem que, no caso dos animais, estes sejam ofensivos a nós seres humanos. Barraza (1998) pontua, também, a influência que os professores exercem no processo de aquisição de percepções sobre o meio ambiente. Dessa forma, é imprescindível uma boa articulação dos mesmos (escola-professoraluno) para, assim, contribuírem para uma aprendizagem mais significativa aos estudantes. 


\section{Conclusões}

As representações ambientais captadas através das redações e dos desenhos demonstraram que os estudantes possuem um conhecimento significativo sobre o ambiente em que vivem. Isso foi exposto quando citaram aspectos da cultura local, como valores, crenças, conflitos locais, a fauna e flora típicas do bioma Cerrado, sentimentos positivos em relação a natureza e ainda o reconhecimento da importância de preservar esse ambiente. Além disso, nos desenhos, os estudantes demonstraram, em sua grande maioria, uma visão naturalista do meio ambiente. Assim, as duas metodologias utilizadas foram importantes, à medida que possibilitaram aos estudantes uma variedade de formas de se expressarem.

Em um contexto de sala de aula, o material didático é uma ferramenta importante para o desenvolvimento das atividades. Dessa forma, ao analisar o livro didático de ciências, percebemos que ele exerceu uma influência significativa nos discursos e representações do sexto e sétimo ano. No entanto, outros meios podem também ter influenciado, como a mídia, a comunidade escola, projetos desenvolvidos na localidade, dentre outros.

Apesar dos estudantes possuírem um grande conhecimento local, foi identificada a importância de ressignificar alguns conceitos adquiridos pelo senso comum, ou por conhecimentos populares, como a questão das queimadas para limpar o pasto. Isso demonstra a importância da realização de intervenções, que possibilitem maior abrangência do conhecimento, contribuindo para uma compreensão mais significativa do ambiente em que estão inseridos. Além disso, o momento foi propício para compartilhar sobre como podem contribuir para a melhoria na qualidade de vida, já que não adianta somente saber que é preciso preservar, é necessário agir e buscar soluções.

A partir desse estudo, sugere-se a implementação de medidas de Educação Ambiental, visto que a comunidade passa por uma crise socioambiental. Também, é de grande importância esse processo de sensibilização para despertar na população uma tomada de consciência a respeito do seu papel como cidadão atuante na sociedade. Nessa perspectiva, a escola exerce um papel fundamental, mas além dela, é necessária a articulação de toda comunidade, a fim de possibilitar a melhores resultados.

\section{Agradecimentos}

Aos pais dos alunos, alunos e professores da Escola Municipal Virgem de Fátima, pela receptividade e presteza. Ao Centro de Reflorestamento de Áreas Degradadas da Universidade Federal do Oeste da Bahia (CRad - UFOB ), pelo apoio logístico para a realização desse trabalho. 


\section{Referências}

AIRES, B. F. C.; BASTOS, R. P. Representações sobre meio ambiente de alunos da Educação Básica de Palmas (TO). Rev. Ciência e educação. v.17. n.2. p. 353-364. 2011.

BARDIN, L. Análise de Conteúdo. Press Universitaires de France. p.38. 1997.

BARRAZA, L. Conservacion y medio ambiente para niños menores de 5 años. Especies (7) p. 19-23. 1998.

BEZERRA, Y. B. S.; PEREIRA, F. S. P.; SILVA, A. K. P.; MENDES, D. G. P. S. M. Análise da Percepção Ambiental de estudantes do ensino fundamental Il em uma escola do Município de Serra Talhada (PE). Revista Brasileira de Educação Ambiental. São Paulo, V. 9. N. 2. 2014.

BONOTTO, D. M. B.; SEMPREBONE, A. Educação Ambiental e educação em valores em livros didáticos de ciências naturais. Ciênc. Educ. (Bauru) v.16 n.1 . 2010.

DAMIANI, M. F.; ROCHEFORT, R. S.; CASTRO, R. F.; DARIZ, M. R.; PINHEIRO, S. S. Discutindo pesquisas do tipo intervenção pedagógica. Cadernos de Educação (UFPel). ed. 45. p. 57-67. 2013.

DIAS, A. A. S.; DIAS, M. A. O. Educação Ambiental: a agricultura como modo de sustentabilidade para a pequena propriedade rural. Revista de Direitos Difusos. v. 68. 2017.

DUTRA, G. K. M.; HIGUCHI, M. I. G. Percepções Ambientais de crianças que vivem em espaços degradados na Amazônia. Ambiente \& Sociedade. São Paulo. v. 21. p. 20. 2018.

FRANCO, A. R.; MORAIS, G. A. C. M.; NETO, J. D.; LOPES, J. C. C.; LEUCAS, H. L. B.; GUADALUPE, D. C.; BARROS, M. D. M. Estudo de Percepção Ambiental com alunos de Escola Municipal localizada no entorno do Parque Estadual da Serra do Rola-Moça. Ambiente \& Educação. v. 17, n.1. 2012.

FREIRE, P. Pedagogia da autonomia: saberes necessários à prática educativa. São Paulo. Paz e Terra. ed. 43. 2011.

HENTZ, P. Eixos norteadores da proposta curricular. Proposta curricular de Santa Catarina: educação infantil, ensino fundamental e médio: temas multidisciplinares. Florianópolis: COGEN, 1998.

LEFEVRE, F.; LEFEVRE, A. M. C. Discurso do Sujeito Coletivo: Representações Sociais e intervenções comunicativas. Texto Contexto- Enferm. Florianópolis. v. 23. n. 2. p. 502-507. 2014.

LUZ, R.; PRUDÊNCIO, C. A. V.; CAIAFA, A. N.; Contribuições da Educação Ambiental crítica para o processo de ensino e aprendizagem em Ciências visando à formação cidadã. Investigações em Ensino de Ciências. v. 23. p. 60-82. 2018. 
MARTINS, F. E.; GUIMARÃES. G. M. A. As concepções de natureza nos livros didáticos de Ciências. Rev. Pesquisa em Educação em Ciências. v. 4. n. 2. p. 14. Dez. 2002.

MAXIMIANO, L. A. Considerações sobre o conceito de paisagem. R. RA'E GA. Editora UFPR. Curitiba. n. 8. p. 83-91. 2004.

MINAYO, M. C. S. ( Org ); DESLANDES, S.F.; NETO, O. C. . GOMES, R. Pesquisa Social. Teoria, método e criatividade. In: MINAYO, M. C. S. Ciência, Técnica e Arte: O Desafio da Pesquisa Social. Petrópolis: Vozes. Cap. I. ed.21. 2002.

MINAYO, M. C. S. In: NETO, O. C. O trabalho de campo como descoberta e criação. Petrópolis, RJ: Vozes. Cap. III. ed. 21. 2002.

MONTEIRO, M. B. Projeto BIOS: a fotografia como elemento de percepção, visão e interferência nas questões ambientais. Em Questão. Porto Alegre. v. 10. n. 2. p. 359-372. 2004.

PEDRINI, A.; COSTA, E. A.; GHILARDI, N. Percepção Ambiental de crianças e pré-adolescentes em vulnerabilidade social para projetos de Educação Ambiental. Ciência \& Educação, v. 16, n. 1, p. 163-179, 2010.

REIGADA, C.; REIS, M. F. C. T. Educação Ambiental para crianças no ambiente urbano: uma proposta de pesquisa-ação. Ciência \& Educação. v. 10. n. 2. p. 149-159. 2004.

ROSSO, Gisele. Queimar pastagem é sinônimo de prejuízo. Empresa Brasileira de Pesquisa Agropecuária. 20 de set. de 2002. Disponível em: https://www.embrapa.br/busca-de-noticias/-/noticia/17931970/queimarpastagem-e-sinonimo-de-prejuizo. Acesso: 21/06/2019.

SANTOS, F. A. S.; ECKERT, N. O. S.; OLIVEIRA, R. S.; NETO, H. G. S.; TEIXEIRA, L. N.; COELHO, A. S. Percepção Ambiental e análise de desenhos: prática em curso de extensão universitária. Revbea. São Paulo, V. 12. N. 2. p.156-177. 2017.

SAUVÉ, L. Educação Ambiental: possibilidades e limitações. Educação e Pesquisa. São Paulo. v. 31. n. 2. p. 317-322. 2005.

SCHWARZ, M. L.; HERRMANN, T. M. TORRI, M. C.; GOLDBERG, L.; "Chuva, como te queremos!": representações sociais da água através dos desenhos de crianças pertencentes a uma região rural semiárida do México. Ciênc. Educ. Bauru. v. 22. n. 3. p. 651-669. 2016.

SILVA, J. S. B.; ANDRADE, W. M.; RAMOS, M. A.; FERRAZ, E. M. N.; SOUTO, W. M.; ALBUQUERQUE, U. P.; ARAÚJO, E. L. Students' perception of urban and rural environmental protection areas in Pernambuco, Brazil. Rev.Tropical Conservation Science, v.8. p. 813-827. 2015.

SILVA, M. M. P. OLIVEIRA, L. A. DINIZ. C. R. CEBALLOS, B. S. O. Educação Ambiental para o uso sustentável de água de cisternas em comunidades rurais da Paraíba. Rev. Bioterra. v. 6. n.1. p. 122-136. 2006. 
SILVA, T. C.; Medeiros, P. M.; Araújo, T. A. S.; Albuquerque, U. P. Northeastern Brazilian students' representations of Atlantic Forest fragments. Springer Science, v. 12. p. 195-211. 2009.

SOUZA, D. V.; ZIONE, F. Novas perspectivas de análise em investigações sobre meio ambiente: a teoria das representações sociais e a técnica qualitativa da triangulação de dados. Saúde e Sociedade, v.12. n.2. p.76-85. 2003.

TELES, P. A. Percepção Ambiental como ferramenta diagnóstica para o processo de integração entre uma Unidade de Conservação e a comunidade do entorno. 2015. 140 p. Programa de Pós-Graduação em Ecologia e Conservação de Recursos Naturais. (Dissertação de Mestrado). Universidade Federal de Uberlândia- MG. 2015.

TUAN, Y. Topofilia: um estudo da percepção, atitudes e valores do meio ambiente. São Paulo: Difel. 1980. 